\title{
Health Insurance Choice with Flexible Spending Accounts
}

\author{
James H. Cardon \\ Department of Economics, Brigham Young University, Provo, Utah, 84602, U.S.
}

I model the interaction of flexible spending accounts (FSAs) and conventional insurance. I show that FSA participation reduces the desired level of insurance coverage. I also show that FSA participation can reduce the total tax cost of health insurance premium and FSA contribution exclusions.

The Geneva Risk and Insurance Review (2012) 37, 208-222. doi:10.1057/grir.2011.9; published online 13 September 2011

Keywords: health insurance; flexible spending accounts; tax cost

Flexible spending accounts (FSA) for healthcare expenses offer an attractive way for U.S. residents to avoid taxes. A recent Kaiser Family Foundation/Health Research and Educational Trust survey of 1,997 public and private employers finds that 73 per cent of large firms $(200+$ employees $)$ and 20 per cent of small firms (3-199 employees) offered such accounts in 2007. ${ }^{1}$

The advantage to the employee can be significant, although there is a financial risk. The advantage is that qualified expenses escape both state and federal income taxation and also all payroll taxes; the risk is that unused funds are forfeited to the employee's firm at the end of the period. Employers also avoid payroll taxes on employee elections.

FSA participation decisions are made concurrently with insurance plan choices each year during the firm's open enrolment period. Therefore, these decisions are made jointly, and with the same information. Because FSAs cover out-of-pocket costs, their availability should have predictable effects on insurance choices. Hamilton and Marton ${ }^{2}$ and Jack et al. ${ }^{3}$ both find evidence that FSA availability is associated with higher cost sharing in employer-sponsored plans.

Schlesinger ${ }^{4}$ extends Mossin's theorem to "upper limit" insurance contracts in which the consumer purchases a fixed level of coverage. Consumers fully

\footnotetext{
${ }^{1}$ Claxton et al. (2007).

${ }^{2}$ Hamilton and Marton (2008).

${ }^{3}$ Jack et al. (2005).

${ }^{4}$ Schlesinger (2006).
} 
insure to the maximum loss if insurance is fairly priced. These are similar in some respects to FSAs. For FSAs, the "premium" per dollar of coverage is independent of risk, depending only on consumer's tax rate. Cardon and Showalter ${ }^{5}$ treat FSAs as a form of supplemental insurance. In that paper, individuals choose FSA participation levels in order to cover their out-ofpocket expenditures, treating the level of insurance coverage as given. Some of the implications for the interaction of insurance with FSA election levels are obvious; for example, if the the consumer has full insurance, the optimal FSA election amount is zero. However, this neglects the effect of FSA election amounts on optimal insurance coverage levels.

This paper extends these results by allowing for endogenous insurance choice. I show that the optimal level of insurance coverage is (weakly) lower with FSA participation if preferences exhibit decreasing or constant absolute risk aversion. In particular, I show when optimal FSA/insurance usage leads to higher deductibles even in cases where insurance is fairly priced. These results are then used to assess the effect of FSA coverage on the tax cost of health benefit exclusions. Finally, I consider the effect of employer subsidies.

\section{Model}

An individual with initial, pre-tax income $I>0$ and marginal tax rate $t$ faces a loss $x \in[0, L]$ where the maximum loss $L<I(1-t)$. The continuous, nondegenerate probability density function ${ }^{6}$ for the loss is $g(x)$ with a distribution function represented by $G(x)$. I assume that $G(x)$ is public information. The individual has preferences defined over consumption $C$, represented by a smooth, concave utility function $U(C)$ with $U^{\prime}>0$ and $U^{\prime \prime}<0$. The individual is eligible to participate in an FSA programme which allows the loss (or a portion of the loss) to be paid out of pre-tax dollars. The FSA election amount $F$ must be chosen prior to the realisation of the loss. The portion of the loss in excess of $F$ is not covered, and unused funds are forfeited. ${ }^{7}$ The model assumes a two-stage choice. In the first stage, the consumer chooses an insurance contract

${ }^{5}$ Cardon and Showalter (2001, 2003).

${ }^{6}$ If the distribution is degenerate such that $x=L$ with probability one, the optimal choice election amount is $L$.

${ }^{7}$ By law, forfeited FSA monies revert to the employer. It is interesting to note that the full election amount must be available immediately, even if the employer allows deductions to be spread evenly across paychecks. This means that an employee could withdraw the full amount after the first paycheck, then quit, leaving the employer with a negative balance. Also, FSAs typically are limited to US\$5,000 per year, although for healthcare FSAs there does not appear to be a legal requirement for such a limit. The 2010 Patient Protection and Affordable Care Act places a US\$2,500 limit (indexed for inflation) on FSA balances, beginning in 2013. I have not 
and an FSA election amount. In the second, conditional on first stage choices and the realised health expenditure, the consumer chooses the withdrawal amount.

I assume that the alternative insurance contract is deductible insurance. Most insurance contracts include a deductible provision, and in typical use FSA funds will first be used to offset the deductible. FSAs work especially well with deductibles because the FSA provides first-dollar coverage of the loss up to the election amount, while a deductible contract covers nothing until the deductible level is reached. In contrast, FSAs do not complement a proportional insurance plan as easily. ${ }^{8}$

\section{Deductible insurance}

In the absence of an FSA, the consumer chooses the deductible level, $D \geqslant 0$, for an insurance contract that pays 100 per cent of losses in excess of the deductible. The premium is $P(D)=(1+\lambda) \int_{D}^{L}(x-D) g(x) d x$, where $\lambda$ is a proportional loading factor. Using integration by parts it can be shown that $P^{\prime}(D)=-(1+\lambda)(1-G(D))$. Let the optimal deductible with no FSA be $D_{0}$. It is well known that the consumer will fully insure at $D_{0}=0$ if insurance is actuarially fair, and will partially insure if it is less than fair. The premium paid by the consumer for employer-provided insurance is excluded from taxable income. Given this implicit tax subsidy, what matters for insurance choice is the "fairness" as perceived by the consumer; that is, the consumer will fully insure if $(1+\lambda)(1-t) \leqslant 1$.

Assume now that the consumer is offered an FSA together with deductible insurance coverage. The level of the deductible is now chosen together with the FSA election amount, $F \geqslant 0$, prior to observing the loss. Once the loss $x$ is realised, the consumer chooses a withdrawal, $W$, which must be less than or equal to the election amount and to total out-of-pocket expenditures. Therefore, given $D, F$ and a realised loss $x$, consumption is $C=(I-P(D)-F)(1-t)+W-\min \{x, D\}$, subject to $W \leqslant F$ and $W \leqslant \min \{x, D\}$. The optimisation problem is therefore:

$$
\max _{D, F, W} E(U(C))
$$

modelled these aspects of the FSA programme to keep the analysis focused on the most essential features of the programme.

${ }^{8}$ An earlier version of this paper also analysed a contract with proportional coinsurance. Results are qualitatively similar but less clean. Jack et al. (2005) also treat the coinsurance case in motivating their empirical work. 
subject to

$$
\begin{gathered}
C=(I-P(D)-F)(1-t)+W-\min \{x, D\}, \\
W \leqslant F, \\
W \leqslant \min \{x, D\},
\end{gathered}
$$

and the non-negativity constraints $F \geqslant 0$ and $D \geqslant 0$.

To simplify the problem, note that once the loss $x$ is revealed, the optimal withdrawal $W^{*}$ satisfies the following:

$$
W^{*}(x)= \begin{cases}x & \text { if } x<F \leqslant D \\ F & \text { if } F \leqslant x<D \\ \min \{F, D\} & \text { if } x \geqslant D \text { and } x \geqslant F\end{cases}
$$

Further, $F \leqslant D$ because FSA balances in excess of the deductible will certainly be forfeited. Given these, we can define $C_{1}=(I-P-F)(1-t)$ for $x<F$, $C_{2}=(I-P)(1-t)+t F-x$ for $F \leqslant x<D$, and $C_{3}=(I-P)(1-t)+t F-D$ for $x \geqslant D$, implying $C_{1} \geqslant C_{2}>C_{3}$. Expected utility is therefore

$$
E U=\int_{0}^{F} U\left(C_{1}\right) g(x) d x+\int_{F}^{D} U\left(C_{2}\right) g(x) d x+\int_{D}^{L} U\left(C_{3}\right) g(x) d x
$$

and the Lagrangian is:

$$
\mathcal{L}(D, F, \mu)=E U+\mu(D-F) .
$$

The Kuhn-Tucker conditions are

$$
\begin{aligned}
\mathcal{L}_{D}= & \int_{0}^{F} U^{\prime}\left(C_{1}\right)(t-1) P^{\prime}(D) g(x) d x+\int_{F}^{D} U^{\prime}\left(C_{2}\right)(t-1) P^{\prime}(D) g(x) d x \\
& +\int_{D}^{L} U^{\prime}\left(C_{3}\right)\left[(t-1) P^{\prime}(D)-1\right] g(x) d x+\mu \leqslant 0 \text { and } D \geqslant 0 \text { w.c.s. }
\end{aligned}
$$


212

$$
\begin{aligned}
& \mathcal{L}_{F}= \int_{0}^{F} U^{\prime}\left(C_{1}\right)(t-1) g(x) d x+\int_{F}^{D} U^{\prime}\left(C_{2}\right) \operatorname{tg}(x) d x \\
&+\int_{D}^{L} U^{\prime}\left(C_{3}\right) \operatorname{tg}(x) d x-\mu \leqslant 0 \text { and } F \geqslant 0 \text { w.c.s. } \\
& \mathcal{L}_{\mu}=D-F \geqslant 0 \text { and } \mu \geqslant 0 \text { w.c.s. }
\end{aligned}
$$

where w.c.s. stands for with complementary slackness.

Proposition 1 The consumer's optimal deductible and FSA election amounts, $D^{*}$ and $F^{*}$, are as follows:

(i) Given $t>0$ and $\lambda>0, D^{*}=F^{*}>0$ and $G\left(D^{*}\right)=\lambda /(1+\lambda)$ if and only if $(1-t)$ $(1+\lambda) \leqslant 1$.

(ii) Given $t>0$ and $\lambda>0, D^{*}>F^{*}>0$ if and only if $(1-t)(1+\lambda)>1$.

(iii) If $t=0$ and $\lambda>0$, then $D^{*}>F^{*}=0$.

(iv) If $\lambda \leqslant 0$, then $D^{*}=F^{*}=0$.

Proof See Appendix.

Proposition 2 The consumer's optimal deductible is (weakly) higher with FSA participation if preferences exhibit constant or decreasing absolute risk aversion.

\section{Proof See Appendix.}

\section{Summary}

Comparative statics results are summarised in Figure 1. The upper panel shows the regions of full and partial deductible insurance without FSA. The curve labelled $(1-t)(1+\lambda)=1$ denotes combinations of $t$ and $\lambda$ for which insurance is actuarially fair, as perceived by the consumer. In the region on or above the curve we have $(1-t)(1+\lambda) \leqslant 1$, and full insurance $D_{0}=0$ is optimal. Otherwise, partial insurance is chosen. With an FSA available, four regions in the lower panel are determined by values of $(t, \lambda)$. If insurance is fair or better $((1-t)(1+\lambda) \leqslant 1), \lambda>0$ and $t>0$, then $D^{*}=F^{*}>0$, and coverage is full but mixed. In this case, the optimal deductible/election amount satisfies $G\left(D^{*}\right)=$ $\lambda /(1+\lambda)$. Note that $D^{*}$ depends only on $\lambda$ and the distribution of losses. For $t>0, \lambda>0$ and unfair insurance $((1-t)(1+\lambda)>1), D^{*}>F^{*}>0$ and the 


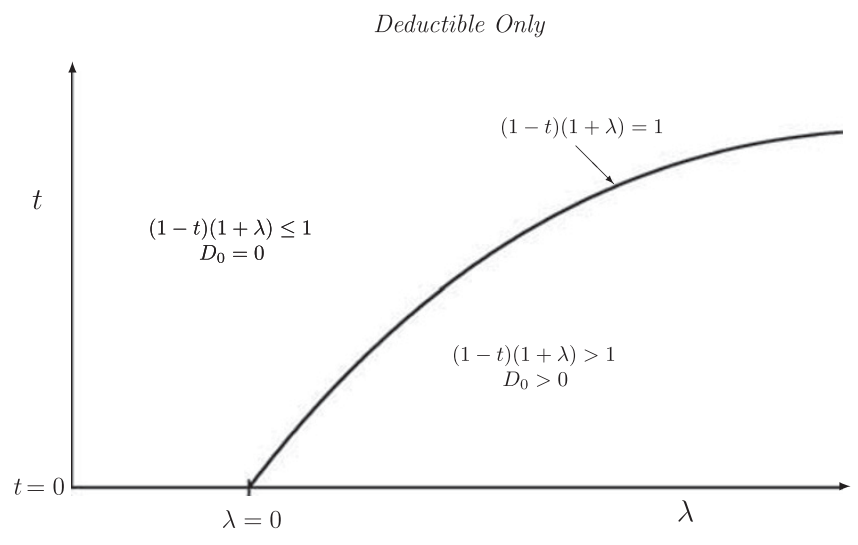

Deductible with FSA

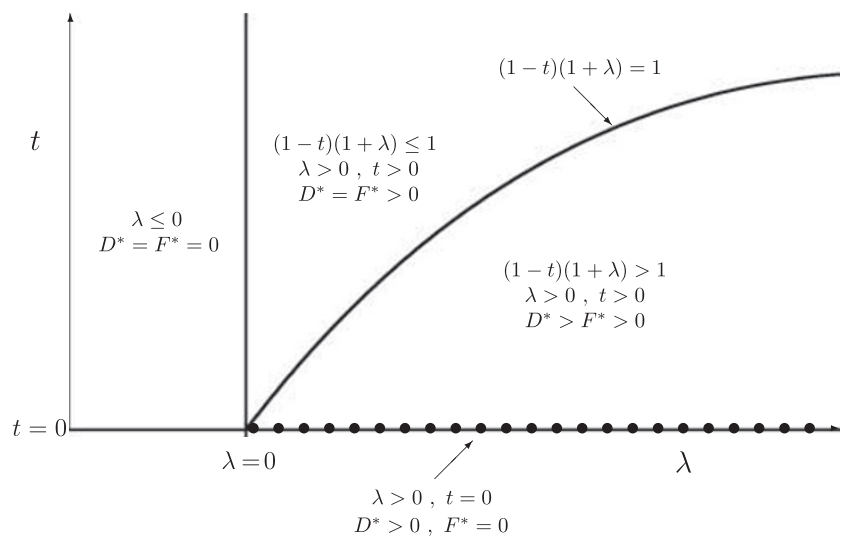

Figure 1. Comparative statics with and without FSAs.

consumer is only partially covered. For $t=0$ and $\lambda>0$, FSAs offer risk (of unused balances) and no reward; hence the optimal choice is partial deductible coverage and no FSA: $D^{*}>F^{*}=0$. This is shown by the dots on the horizontal axis. For any value of $t$, if $\lambda \leqslant 0$, which might happen if the employer pays a portion of the insurance premium, then $D^{*}=F^{*}=0$.

When $(1-t)(1+\lambda) \leqslant 1$ the consumer would, in the absence of an FSA, choose full deductible coverage, $D_{0}=0$. In contrast, a consumer with an FSA option will, given $\lambda>0$ and $t>0$, raise the deductible and compensate with some level of $F^{*} \leqslant D^{*}$. The reason for this is that FSA "premium" per unit of coverage is constant at $1-t$, while the insurance premium is non-linear in $D$. 
In particular, at $D=0$ we have $-P^{\prime}(0)(1-t)=(1+\lambda)(1-t)>1-t$. Therefore, an increase in both $D$ and $F$ raises expected utility over full deductible coverage. In summary, if $t>0$ and $\lambda>0$ the optimal deductible is higher when an FSA is available, or $D^{*}>D_{0}$.

\section{Tax revenue costs of FSA participation}

Federal and state law exempts certain health insurance premiums as well as FSA election amounts from taxes, which represents a substantial cost in reduced tax revenue. Sheils and Haught ${ }^{9}$ estimate a total state and federal tax cost for all health benefit exclusions of US\$209.9 billion for 2004. The federal income tax exclusion for insurance alone is US\$101 billion, or 53.6 per cent of the federal total. Reimbursement accounts, which include health reimbursement arrangements (HRAs) as well as FSAs, have an estimated federal tax cost of US\$1.6 billion. In order to reduce these costs, the recently passed 2010 Patient Protection and Affordable Care Act places a US\$2,500 limit (indexed for inflation) on FSA balances, beginning in 2013. ${ }^{10}$

The marginal tax rate $t$ that is relevant in determining a consumer's optimal choices $F^{*}$ and $D^{*}$ includes only taxes paid by the consumer. To determine the overall tax cost we must also include the portion of payroll taxes paid by the employer. Define $\tau \geqslant t$ as the sum of employer and consumer tax rates. Further, unused balances are forfeited to the employer and may be taxable depending on how the employer uses these funds. ${ }^{11}$ Let the tax rate on forfeited funds be $\hat{\tau}$. The actual tax cost of FSAs is difficult to determine. If we take the deductible or other cost-sharing provisions of an insurance contract as exogenous, then we can estimate the tax cost as $\tau F^{*}$. But if FSA usage leads to reduced insurance coverage, as shown above, then there will be an offsetting reduction in tax costs from lower insurance premium exclusions. The results from the previous section are used to assess the true tax cost of FSAs.

\section{Deductible insurance with proportional loading}

In case $(i)$ from Proposition $1, t>0, \lambda>0$ and $(1-t)(1+\lambda) \leqslant 1$, implying $D^{*}=F^{*}>0$ and $G\left(D^{*}\right)=\lambda /(1+\lambda)$. In contrast, the optimal deductible without FSA is $D_{0}=0$. The change in tax revenue cost $(T C)$ depends on the premium

\footnotetext{
${ }^{9}$ Sheils and Haught (2004).

${ }^{10}$ USGPO (2010).

11 The employer has a number of options for allocating forfeited funds or "experience gains", some of which may be taxable (see IRS, 2003).
} 
difference and the tax subsidy on the FSA balance:

$$
\begin{aligned}
\Delta T C= & \tau\left[P\left(D^{*}\right)-P\left(D_{0}\right)\right]+\tau F^{*}-\hat{\tau} \int_{0}^{F^{*}}\left(F^{*}-x\right) g(x) d x \\
= & \tau(1+\lambda) \int_{D^{*}}^{L}\left(x-D^{*}\right) g(x) d x-\tau(1+\lambda) \\
& \times \int_{D_{0}}^{L}\left(x-D_{0}\right) g(x) d x+\tau F^{*}-\hat{\tau} \int_{0}^{F^{*}}\left(F^{*}-x\right) g(x) d x .
\end{aligned}
$$

Using $G\left(D^{*}\right)=\lambda /(1+\lambda)$ and simplifying yields

$$
\begin{aligned}
\Delta T C & =-\tau(1+\lambda)\left[\int_{0}^{D^{*}} x g(x) d x\right]-\hat{\tau} \int_{0}^{F^{*}}\left(F^{*}-x\right) g(x) d x \\
& =-\tau \lambda E\left(X \mid X \leqslant D^{*}\right)-\hat{\tau} \int_{0}^{F^{*}}\left(F^{*}-x\right) g(x) d x<0 .
\end{aligned}
$$

In this case, FSA participation raises the deductible to the same level as that of the FSA election amount, and the reduction in tax cost comes from the fact that insurance carries a positive loading factor. Despite the fact that insurance is better-than-fair because of the tax subsidy, FSA participation creates the incentive to switch coverage to FSA balances.

For case $(i i)$, if $t>0, \lambda>0$ and $(1-t)(1+\lambda)>1$, then $D^{*}>F^{*}>0$. Here, there is a gap between $F^{*}$ and $D^{*}$. The revenue cost of FSA is $\Delta T C=\tau\left[P\left(D^{*}\right)-\right.$ $\left.P\left(D_{0}\right)\right]+\tau F^{*}$, or

$$
\begin{aligned}
\Delta T C= & \tau(1+\lambda) \int_{D^{*}}^{L}\left(x-D^{*}\right) g(x) d x-\tau(1+\lambda) \int_{D_{0}}^{L}\left(x-D_{0}\right) g(x) d x \\
& +\tau F^{*}-\hat{\tau} \int_{0}^{F^{*}}\left(F^{*}-x\right) g(x) d x \\
= & \tau(1+\lambda)\left[D_{0}\left(1-G\left(D_{0}\right)\right)-D^{*}\left(1-G\left(D^{*}\right)\right)-\int_{D_{0}}^{D^{*}} x g(x) d x\right] \\
& +\tau F^{*}-\hat{\tau} \int_{0}^{F^{*}}\left(F^{*}-x\right) g(x) d x .
\end{aligned}
$$


216

Here the sign of $\triangle T C$ is ambiguous, but it is clear that $\Delta T C \leqslant \tau F^{*}$ since $D^{*} \geqslant D_{0}$ by Proposition 2. The first two terms will be negative if

$$
\frac{\partial D(1-G(D))}{\partial D}=1-D g(D)-G(D)>0
$$

Rearranging yields the condition

$$
\frac{1-G(D)}{g(D)}>D
$$

This is just the condition that the Mills Ratio $(D)>D$. Finally, for cases (iii) and (iv) there is no change in tax revenue, since the optimal FSA election amount is zero and, therefore, the deductible choice is unchanged.

\section{Fixed loading}

I have made the usual assumption that insurance loading is proportional to the premium. If, however, a source of the loading is fixed underwriting costs, then the marginal loading may be lower than the average. In the extreme case of purely fixed loading, $P^{\prime}(D)=-(1-G(D))$, and there is no difference in tax cost at the margin.

\section{Insurance options and employer subsidies}

FSAs are offered through employers along with a menu of insurance options. Many employers offer generous insurance subsidies. Suppose the employer subsidises a fraction $0 \leqslant s \leqslant 1$ of the insurance premium. Then (2) is replaced with

$$
C=(I-(1-s) P(D)-F)(1-t)+W-\min \{x, D\} .
$$

The condition for full insurance becomes $(1-s)(1+\lambda)(1-t) \leqslant 1$ or $\left(1+\lambda^{\prime}\right)$ $(1-t) \leqslant 1$, where $\lambda^{\prime}=\lambda(1-s)-s$. The results of Proposition 1 hold if we replace $\lambda$ with $\lambda^{\prime}$. Then full deductible insurance and zero FSA is likely to be the common outcome, since $\lambda^{\prime}$ will typically be negative. ${ }^{12}$

${ }^{12}$ According to the Medical Expenditure Panel Survey (AHRQ, 2008), the U.S. average for the fraction of family premiums paid by employers is about 72.4 per cent, while for single premiums the fraction is 79.9 per cent. Using $s=0.75$ as a crude estimate of a proportional subsidy and assuming a true loading factor of $\lambda=0.3$, we see that $\lambda^{\prime}=-0.675$. 
Under current law, however, employers are permitted to make contributions to employee FSAs. A proportional match of employee contributions at the same rate $s$ acts just as a subsidy and the resulting consumption equation is

$$
C=(I-(1-s)(P(D)-F))(1-t)+W-\min \{x, D\} .
$$

Since the subsidies are equal for both insurance and FSA, it is easily seen that $D^{*}=F^{*}=0$ is not optimal, and the consumer will always choose mixed coverage.

If, instead, employers use a fixed insurance subsidy $S$ and offer no FSA subsidy, consumption becomes

$$
C=(I-P(D)+\min \{P(D), S\}-F)(1-t)+W-\min \{x, D\} .
$$

The subsidy will not affect the price of insurance at the margin because the consumer will always choose a deductible low enough to use all of the subsidy. Let $S$ be the subsidy amount and let $\bar{D}$ be the deductible level that solves $P(\bar{D})=S$. It is clear that the optimal deductible $D^{*} \leqslant \bar{D}$. Suppose that $S$ is low, so that $D^{*}<\bar{D}$. In this case, the subsidy is simply an increase in income and we have

$$
C=(I+S-P(D)-F)(1-t)+W-\min \{x, D\} .
$$

Then the results of Proposition 1 hold qualitatively, with the only difference being an income that is higher by $S$. If the subsidy is high, then $D^{*}=\bar{D}$ and the subsidy determines the deductible. The optimal FSA level will then be chosen for that level of deductible, and the results in Cardon and Showalter ${ }^{5}$ hold.

\section{Employer insurance pools and asymmetric information}

The models above predict that employees with high levels of subsidies will choose full insurance, and that FSA election amounts would be zero. However, insurance markets are often characterised by asymmetric information in the form of adverse selection or moral hazard. The insurance options offered to employees reflect market responses to these information problems. With adverse selection, employers offer a menu of contracts of varying coverage levels (say, high and low deductibles) in order to separate high and low risk types. ${ }^{13}$

${ }^{13}$ See Rothschild and Stiglitz (1976) for the classic treatment. Cardon (2010) shows the interaction of FSAs with insurance with adverse selection. FSA availability changes the separating equilibrium, making it harder to sustain. FSAs can, on the other hand, produce a better outcome in employer insurance pools by allowing more flexibility. 
With moral hazard, optimal contracts use cost-sharing in order to reduce over-consumption. In both these cases, employees cannot freely choose their levels of coverage, and full coverage is rarely offered. If $D$ is fixed or chosen from a menu of options, then the consumer's problem is somewhat simplified and $F$ might be thought of as simply a supplement to a fixed level of costsharing.

Alternatively, assume that insurance plan characteristics (cost-sharing and subsidy levels) are chosen along with the employee's income in order to attain a fixed level of compensation, as determined by a competitive labour market. Then FSA availability will likely lead to both a higher income and a higher deductible in anticipation of an offsetting FSA contribution by the employee. The firm's choice of income/benefits mix will reflect the underlying preferences of the employees, as given by the model above.

\section{Conclusion}

This paper has extended a simple model of FSA participation to examine the joint choice of insurance contracts and FSA election amounts. I have shown that FSAs do raise optimal deductible levels in some cases. This is most obvious in the case of deductible insurance, where the optimal deductible is positive even for better-than-fair insurance so long as tax rates and loading factors are positive. FSAs can be an attractive substitute for insurance when loading factors are high, but this is undermined by employer subsidies of insurance. FSA availability also has the potential to lower the tax cost of health subsidies, and estimates of FSA tax cost will be inflated if they do not account for the effect of FSA participation on insurance contract choices.

\section{Acknowledgements}

I thank Art Snow, Rulon Pope and Mark Showalter for their helpful comments.

\section{References}

Agency for Healthcare Research and Quality, Center for Financing, Access and Cost Trends (2008) 2008 Medical Expenditure Panel Survey-Insurance Component. Summary data tables I.C.3 and I.D.3.

Cardon, J.H. (2010) 'Flexible spending accounts and adverse selection', The Journal of Risk and Insurance 77(1): 145-153.

Cardon, J.H. and Showalter, M. (2001) 'An examination of flexible spending accounts', Journal of Health Economics 20: 935-954.

Cardon, J.H. and Showalter, M. (2003) 'Flexible spending accounts as insurance', Journal of Risk and Insurance 70: 43-51. 
Claxton, G., Gabel, J., DiJulio, B., Pickreign, J., Whitmore, H., Finder, B., Jacobs, P. and Hawkins, S. (2007) 'Health benefits in 2007: Premium increases fall to an eight-year low, while offer rates and enrollment remain stable', Health Affairs 26(5): 1407-1416.

Hamilton, B.H. and Marton, J. (2008) 'Employee choice of flexible spending account participation and health plan', Health Economics 17: 793-813.

Internal Revenue Service (2003) 'Internal revenue bulletin: 2007-39', from http://www.irs.gov/irb/ 2007-39_IRB/ar14.html, accessed 24 September 2007.

Jack, W., Levinson, A. and Rahardja, S. (2005) Employee cost-sharing and the welfare effects of flexible spending accounts. NBER Working Paper 11315.

Rothschild, M. and Stiglitz, J. (1976) 'Equilibrium in competitive insurance markets', Quarterly Journal of Economics 90: 629-649.

Schlesinger, H. (2006) 'Mossin's theorem for upper-limit insurance policies', The Journal of Risk and Insurance 73: 297-301.

Sheils, J. and Haught, R. (2004) 'The cost of tax-exempt health benefits in 2004', Health AffairsWeb Exclusive W4-107, from http://content.healthaffairs.org/cgi/reprint/hlthaff.w4.106v1, accessed 25 February 2004.

U.S. Government Printing Office (2010) 'Patient protection and affordable care act', from http://www.gpo.gov/fdsys/pkg/PLAW-111publ148/pdf/PLAW-111publ148.pdf.

\section{Appendix}

Proofs of Propositions 1 and 2

\section{Proof of Proposition 1}

To prove (i) and (ii), assume $t>0$ and $\lambda>0$. If $F^{*}=D^{*}$, then (5) and (6) become

$$
\mathcal{L}_{D}=U^{\prime}\left(C_{1}\right)[(1-t)(1+\lambda)-1]\left(1-G\left(D^{*}\right)+\mu \leqslant 0\right.
$$

and

$$
\mathcal{L}_{F}=U^{\prime}\left(C_{1}\right)\left[t-G\left(D^{*}\right)\right]-\mu \leqslant 0,
$$

which imply $\lambda /(1+\lambda) \leqslant G\left(D^{*}\right) . \quad D^{*}=0$ implies $\lambda /(1+\lambda) \leqslant 0$, contradicting $\lambda>0$. Hence $D^{*}=F^{*}>0$, and therefore (5) and (6) hold with equality and $\lambda /(1+\lambda)=G\left(D^{*}\right)$. Since $\mu \geqslant 0$, (A.1) implies

$$
(1-t)(1+\lambda) \leqslant 1
$$

Instead, if $F^{*}<D^{*}$ the constraint $F \leqslant D$ is not binding and $\mu=0<D^{*}$, so (5) holds with equality. If $F=0, D^{*}>0$ and $\mu=0$, we have $\mathcal{L}_{F}>0$, contradicting (6). 
220

Hence $0<F^{*}<D^{*}$. Also, (5) implies

$$
(1-t)(1+\lambda)=\frac{U^{\prime}\left(C_{3}\right)}{U^{\prime}\left(C_{1}\right) G\left(F^{*}\right)+\int_{F}^{D} U^{\prime}\left(C_{2}\right) g(x) d x+U^{\prime}\left(C_{3}\right)\left(1-G\left(D^{*}\right)\right)}>1
$$

The inequality follows because $U^{\prime}\left(C_{1}\right)<U^{\prime}\left(C_{2}\right) \leqslant U^{\prime}\left(C_{3}\right)$ implies that the denominator is less than $U^{\prime}\left(C_{3}\right)$. Now (A.4) implies $F^{*}<D^{*}$ since $F^{*}=D^{*}$ implies (A.3). Given (A.3) we must have $F^{*}=D^{*}$ since $F^{*}<D^{*}$ implies (A.4). This proves parts $(i)$ and $(i i)$.

To prove (iii), note that $t<0$ implies $\mathcal{L}_{F}<0$ for any $F>0$, since there is a risk of forfeiture and no tax advantage, hence $F^{*}=0$. Then at $D=0$ we have $\mathcal{L}_{D}=\lambda U^{\prime}\left(C_{3}\right)+\mu>0$. Therefore $D^{*}>0$ if $\lambda>0$.

To prove (iv), note that $\lambda \leqslant 0$ implies $(1-t)(1+\lambda) \leqslant 1$. Then (A.4) cannot hold and we must have $D^{*}=F^{*}$. If $D^{*}=F^{*}>0$, then $G\left(D^{*}\right)=\lambda /(1+\lambda)$ for $\lambda>0$, but this cannot hold for $\lambda \leqslant 0$. Therefore $D^{*}=F^{*}=0$.

\section{Proof of Proposition 2}

In case $(i)$ above, $D^{*}>D_{0}=0$. In cases (iii) and (iv), $F^{*}=0$, and therefore the availability of FSAs induces no change. However, in case (ii) where $t>0, \lambda>0$ and $(1-t)(1+\lambda)>1$, both $D_{0}$ and $F^{*}$ are strictly positive. To show that $D^{*}>D_{0}$ in this region of the parameter space, it is sufficient to treat $F$ as a parameter and show that $D^{*}$ is increasing in $F$. Define $C_{1}=(I-P-F)(1-t)$ for $x<F, C_{2}=(I-P)(1-t)+t F-x$ for $F \leqslant x \leqslant D$, and $C_{3}=(I-P)(1-t)+t F-D$ for $x>D$.

The first-order condition for $D$ when $D>0$ is

$$
\begin{aligned}
\frac{\partial E U}{\partial D}= & \int_{0}^{F} U^{\prime}\left(C_{1}\right)(t-1) P^{\prime}(D) g(x) d x+\int_{F}^{D} U^{\prime}\left(C_{2}\right)(t-1) P^{\prime}(D) g(x) d x \\
& +\int_{D}^{L} U^{\prime}\left(C_{3}\right)\left[(t-1) P^{\prime}(D)-1\right] g(x) d x=0 .
\end{aligned}
$$

Note that the first two terms are strictly positive, which implies that $(t-1) P^{\prime}(D)-1=(1-t)(1+\lambda)(1-G(D))-1<0$ for an interior solution. 
Differentiating the first-order condition we have

$$
\begin{aligned}
\frac{\partial^{2} E U}{\partial F \partial D}= & \int_{0}^{F} U^{\prime \prime}\left(C_{1}\right)(t-1)^{2} P^{\prime}(D) g(x) d x+\int_{F}^{D} U^{\prime \prime}\left(C_{2}\right) t(t-1) \\
& \times P^{\prime}(D) g(x) d x+\int_{D}^{L} U^{\prime \prime}\left(C_{3}\right) t\left((t-1) P^{\prime}(D)-1\right) g(x) d x .
\end{aligned}
$$

Using standard CS analysis, $\partial D / \partial F$ has the same sign as $\partial^{2} E U / \partial F \partial D$. The first term is positive, the second negative and the third is positive. The Arrow-Pratt measure of absolute risk aversion is

$$
r(C)=-\frac{U^{\prime \prime}(C)}{U^{\prime}(C)}
$$

and preferences are said to exhibit decreasing absolute risk aversion (DARA) if $r^{\prime}(C)<0$ and constant absolute risk aversion (CARA) if $r^{\prime}(C)=0$. Using $U^{\prime \prime}(C)=-r(C) U^{\prime}(C)$ we can rewrite (A.5) as

$$
\begin{aligned}
\frac{\partial^{2} E U}{\partial F \partial D}= & \int_{0}^{F}-r\left(C_{1}\right) U^{\prime}\left(C_{1}\right)(t-1)^{2} P^{\prime}(D) g(x) d x+\int_{F}^{D}-r\left(C_{2}\right) U^{\prime}\left(C_{2}\right) t(t-1) \\
& \times P^{\prime}(D) g(x) d x+\int_{D}^{L}-r\left(C_{3}\right) U^{\prime}\left(C_{3}\right) t\left((t-1) P^{\prime}(D)-1\right) g(x) d x
\end{aligned}
$$

then rearrange to obtain

$$
\begin{aligned}
\frac{\partial^{2} E U}{\partial F \partial D}= & t \int_{0}^{F}-r\left(C_{1}\right) U^{\prime}\left(C_{1}\right)(t-1) P^{\prime}(D) g(x) d x+t \int_{F}^{D}-r\left(C_{2}\right) U^{\prime}\left(C_{2}\right)(t-1) \\
& \times P^{\prime}(D) g(x) d x+t \int_{D}^{L}-r\left(C_{3}\right) U^{\prime}\left(C_{3}\right)\left((t-1) P^{\prime}(D)-1\right) g(x) d x \\
& +\int_{0}^{F} r\left(C_{1}\right) U^{\prime}\left(C_{1}\right)(t-1) P^{\prime}(D) g(x) d x .
\end{aligned}
$$


Since the last term is positive, we have

$$
\begin{aligned}
\frac{\partial^{2} E U}{\partial F \partial D}> & t \int_{0}^{F}-r\left(C_{1}\right) U^{\prime}\left(C_{1}\right)(t-1) P^{\prime}(D) g(x) d x+t \int_{F}^{D}-r\left(C_{2}\right) U^{\prime}\left(C_{2}\right)(t-1) \\
& \times P^{\prime}(D) g(x) d x+t \int_{D}^{L}-r\left(C_{3}\right) U^{\prime}\left(C_{3}\right)\left((t-1) P^{\prime}(D)-1\right) g(x) d x .
\end{aligned}
$$

The first two terms are negative and the last is positive (as noted above). Define $C^{*}$ as $C$ at which $x$ equals $D$. Since $C_{1} \geqslant C_{2}>C^{*}=C_{3}$, DARA implies $r\left(C_{1}\right) \leqslant r\left(C_{2}\right)<r\left(C^{*}\right)=r\left(C_{3}\right)$ and CARA implies $r\left(C_{1}\right)=r\left(C_{2}\right)=r\left(C^{*}\right)=r\left(C_{3}\right)$. Therefore we have

$$
\begin{aligned}
\frac{\partial^{2} E U}{\partial F \partial D}> & r\left(C^{*}\right) t\left[\int_{0}^{F}-U^{\prime}\left(C_{1}\right)(t-1) P^{\prime}(D) g(x) d x+\int_{F}^{D}-U^{\prime}\left(C_{2}\right)(t-1)\right. \\
& \left.\times P^{\prime}(D) g(x) d x+\int_{D}^{L}-U^{\prime}\left(C_{3}\right)\left((t-1) P^{\prime}(D)-1\right) g(x) d x\right] \\
\geqslant & r\left(C^{*}\right) t\left[-\frac{\partial E U}{\partial D}\right]=0
\end{aligned}
$$

\section{About the Author}

James H. Cardon obtained his PhD in Economics from Princeton University in 1996. His major fields of interest are health economics and industrial organisation. He is Associate Professor of Economics at Brigham Young University (6/02-present) and was Assistant Professor of Economics at Brigham Young University from August 1996 to June 2002. 